\title{
Are Improvements Still Needed to the Modified Hospital Readmissions Reduction Program: a Health and Retirement Study (2000-2014)?
}

\author{
Charleen Hsuan, JD, $P h D^{\top}$ (D) Thomas M. Braun, $P h D^{2}$, Ninez A. Ponce, PhD, MPP ${ }^{3}$, and \\ Geoffrey J. Hoffman, $P h D^{4}$
}

\begin{abstract}
'Department of Health Policy and Administration, Pennsylvania State University, University Park, PA, USA; ${ }^{2}$ Department of Biostatistics, University of Michigan School of Public Health, Ann Arbor, MI, USA; ${ }^{3}$ Department of Health Policy and Administration, University of California, Los Angeles Fielding School of Public Health, Los Angeles, CA, USA; ${ }^{4}$ Department of Systems, Populations and Leadership, University of Michigan School of Nursing, Ann Arbor, MI, USA.
\end{abstract}

\begin{abstract}
BACKGROUND: To address concerns that the Hospital Readmissions Reduction Program (HRRP) unfairly penalized safety net hospitals treating patients with high social and functional risks, Medicare recently modified HRRP to compare hospitals with similar proportions of high-risk, dual-eligible patients ("peer group hospitals"). Whether the change fully accounts for patients' social and functional risks is unknown.
\end{abstract}

OBJECTIVE: Examine risk-standardized readmission rates (RSRRs) and hospital penalties after adding patient-level social and functional and community-level risk factors.

DESIGN: Using 2000-2014 Medicare hospital discharge, Health and Retirement Study, and community-level data, latent factors for patient social and functional factors and community factors were identified. We estimated RSRRs for peer groups and by safety net status using four hierarchical logistic regression models: "base" (HRRP model); "patient" (base plus patient factors); "community" (base plus community factors); and "full" (all factors). The proportion of hospitals penalized was calculated by safety net status.

PATIENTS: 20,255 fee-for-service Medicare beneficiaries $(65+)$ with eligible index hospitalizations

MAIN MEASURES: RSRRS

KEY RESULTS: Half of safety net hospitals are in peer group 5. Compared with other hospitals, peer group 5 hospitals (most dual-eligibles) treated sicker, more functionally limited patients from socially disadvantaged groups. RSRRs decreased by $0.7 \%$ for peer groups 2 and 4 and $1.3 \%$ for peer group 5 under the patient and full (versus base) models. Measured performance improved after adjusting for patient risk factors for hospitals in peer group 4 and 5 hospitals, but worsened for those in peer groups 1, 2, and 3. Under the patient (versus base) model,

The paper was presented virtually at the AcademyHealth Annual Research Meeting on August 4, 2020, and at the American Public Health Association Annual Meeting and Expo on October 24-28, 2020.

Electronic supplementary material The online version of this article (https://doi.org/10.1007/s11606-020-06222-1) contains supplementary material, which is available to authorized users.

Received February 21, 2020

Accepted September 7, 2020

Published online October 13, 2020 fewer safety net hospitals (48.7\% versus $51.3 \%$ ) but more non-safety net hospitals (50.0\% versus $49.1 \%)$ were penalized.

CONCLUSIONS: Patient-level risk adjustment decreased RSRRs for hospitals serving more at-risk patients and proportion of safety net hospitals penalized, while modestly increasing RSRRs and proportion of non-safety net hospitals penalized. Results suggest HRRP modifications may not fully account for hospital variation in patientlevel risk.

KEY WORDS: readmissions; safety net hospitals; social risk.

J Gen Intern Med 35(12):3564-71

DOI: $10.1007 /$ s11606-020-06222-1

(c) Society of General Internal Medicine 2020

\section{INTRODUCTION}

Medicare's Hospital Readmission Reduction Program (HRRP), which penalizes hospitals with higher-thanexpected readmissions, does not risk adjust for hospital differences in patient social and functional risks, or community factors such as access to care. This omission led to concerns that the program attributed patient- and community-level risks outside of hospitals' control to gaps in hospital quality, ${ }^{1,2}$ resulting in higher risk-standardized readmission rates (RSRRs) and penalties for safety net hospitals treating more at-risk patients. ${ }^{3}$ In 2019, the HRRP implemented a stratification approach designed to adjust for unmeasured social and clinical risks. ${ }^{4}$ Specifically, instead of comparing each hospital's performance with all other hospitals, the modified HRRP compares each hospital's performance with other hospitals in its "peer group," defined as hospitals treating similar proportions of patients dually eligible for Medicare and Medicaid. ${ }^{5}$

It is unknown whether this policy change adequately addresses critics' concerns. Patients dually eligible for Medicare and Medicaid are more likely than other patients to have poor health status; greater social, cognitive, and functional risks ${ }^{6}$; and higher likelihood of readmission, ${ }^{3,7}$ so modifications may be sufficient. Indeed, one of the few studies directly examining the new methodology observed that substantially fewer safety 
net hospitals were penalized under the modified compared with original methodology. This difference was particularly pronounced for hospitals treating the highest proportion of patients dually eligible for Medicaid and Medicare, where the proportion of hospitals penalized for any HRRP condition decreased by $15 \%{ }^{8}$ Nonetheless, the modified methodology may not fully account for differences in social or functional risk. This is because, unlike risk adjustment using patient factors, stratification by peer group is based on a single hospital-level factor (proportions of dually eligible patients) that may reflect only part of the risk associated with readmissions. ${ }^{9,10}$ If so, the stratification approach may still unfairly penalize hospitals with high proportions of at-risk patients, including safety net hospitals.

Previous research reported that including patient social and functional factors and community factors as additional risk adjustors in the original HRRP methodology further explained readmission risk. ${ }^{1,11-15}$ For instance, one study suggested over $50 \%$ of readmission risk may be due to patient factors, including sociodemographics and health status, ${ }^{11}$ and another suggested about a third of readmission risk may be due to community factors. ${ }^{13}$

To our knowledge, previous research has not examined whether the modified HRRP, which uses a hospital-level proxy, fully captures differences in patient social and functional factors and community risk. Our goal was to examine whether the modified HRRP adequately accounts for these risk factors for safety net hospitals, which typically serve the most at-risk patient populations. To do so, we examined patient and community differences between hospitals in different peer groups, calculated average RSRRs after adjusting for patient and community risk factors, and compared whether safety net and non-safety net hospitals would be differentially penalized under the modified HRRP, using a unique dataset that contains Medicare claims and linked survey data. We hypothesized that the stratification approach would not sufficiently account for differences in patient social and functional factors and community factors, so expected that risk adjustment for these factors would reduce differences in RSRRs and proportion of safety net hospitals that were penalized.

\section{METHODS}

\section{Data and Sample}

We used Medicare hospital data (January 2000 to August 2015), linked by discharge to the Health and Retirement Study (HRS); by hospital to the 2017 CMS' New Stratified Methodology Impact File; and by patient county of residence to the Area Health Resources File (AHRF) (2000 2015). The HRS, a nationally representative longitudinal panel survey of older Americans with detailed patient sociodemographic, health, functioning, and economic characteristics, has previously been used to study HRRP. ${ }^{14,15}$
The Impact File stratified hospitals into five peer groups (quintiles) based on the proportion of Medicare stays where the patient is dually eligible for Medicare and full-benefit Medicaid, with peer group 1 reflecting hospitals with the fewest dual-eligibles and peer group 5 the most. We also used the Impact File to categorize safety net hospitals, following prior work as those with the highest quartile of the disproportionate share hospital (DSH) patient percentage. ${ }^{16}$ The datasets used in the current study are not publicly available due to patient confidentiality, but are available from CMS and the HRS Survey Research Center.

Our study population was a cohort of eligible index hospitalizations for older $(\geq 65)$ fee-for-service Medicare beneficiaries in 1754 hospitals, defined using CMS criteria ${ }^{17}$ (Appendix 1). HRRP methodology calculates the expected readmission rate for all hospitals, but does not calculate RSRRs or penalties for hospitals with a small number of index hospitalizations. We followed this methodology, using all 1754 hospitals to calculate the expected readmission rates, but only calculated and reported RSRRs and penalties for 441 hospitals with at least 15 index discharges in the HRS data during the study period.

\section{Measures}

We had two main outcome measures. The first was the riskstandardized readmission rate (RSRR), which we generated using CMS' hospital-wide 30-day unplanned readmission methodology, which excludes planned readmissions (e.g., chemotherapy) ${ }^{17}$ (details below). The hospital-wide readmission methodology generates a single RSRR per hospital. We also generated RSRRs by peer group and by safety net status. The second outcome measure was the proportion of hospitals penalized, by safety net status.

The main predictor variables were seven latent factors representing patient-level and community-level factors (Appendix Table 1). We used confirmatory factor analysis to reduce the number of variables, address concerns about overfitting, and aid in interpretability. Variables were observed patient- and community-level characteristics previously linked with readmission risk. ${ }^{12,18-20}$ The four patient-level latent factors, from HRS data, represent patient health status, functional/health status, frailty, and socioeconomic status. The three community-level latent factors, from AHRF data, represent access to care, area income, and area education.

\section{Analysis}

Our goals were to (a) compare patient and community characteristics of hospitals in different peer groups using appropriate tests (e.g., ANOVA); (b) examine how adjusting for patient- and community-level characteristics influenced readmission performance within the peer groups and for safety net and non-safety net hospitals; and (c) examine how adjusting for these characteristics influenced the proportion of penalized hospitals. 
RSRRs. We followed the CMS approach to calculate the RSRRs (Appendix 1). Using a hierarchical generalized linear model (HGLM), we estimated the predicted and expected number of readmissions. We calculated the excess readmission ratio (ERR), or the ratio of predicted-to-expected readmissions, and converted them to RSRRs by multiplying by the national observed readmission rate. The expected probability of readmissions is based on the full sample of 1754 hospitals, but the ERRs and RSRRs are only calculated for the 441 hospitals with at least 15 index discharges during the study period.

We calculated ERRs and RSRRs under the following: (a) the base model; (b) base model plus patient social and functional factors (the "patient" model); (c) base model plus community factors (the "community" model); and (d) all factors (the "full" model). Our base model, similar to the HRRP model, controlled for age, sex, and clinical risk using the Charlson comorbidity index ("base model"). ${ }^{21}$ Models (b)-(d) added patient and community latent factors as indicated. The patient and full models also included variables controlling for patient race/ethnicity and marital and educational status. All four models use the same sample.

Within each peer group, we calculated the RSRRs for each of the four models and plotted them on waterfall plots. If the modified HRRP fully captured variability in patient and community risk factors, there would be little difference in the plots. We also examined the average change in rankings by peer group under the patient, community, and full models (compared with the base model).

To determine the proportion of safety net and non-safety net hospitals penalized, we calculated the percentage of safety net and non-safety net hospitals receiving penalties under each model under the modified HRRP. The modified HRRP methodology penalized hospitals if their ERR is above the median ERR of that hospital's peer group. ${ }^{5}$ For comparison, in supplementary analyses, we calculated the percent of hospitals penalized under the original HRRP.

This study was approved by [University of Michigan] institutional review board.

\section{RESULTS}

\section{Unadjusted Patient and Community Characteristics by Hospital Peer Group}

The sample consisted of 20,255 eligible index hospitalizations across 441 hospitals. Patients across the five hospital peer groups differed by social, functional, and community factors. Peer group 5 hospitals (most dual-eligibles) treated sicker, more functionally limited patients from socially disadvantaged groups compared with peer group 1 hospitals. For example, patients in peer group 5 (versus peer group 1) hospitals were four times more likely to be African-American (29.8\% versus $7.8 \%, p<0.001$ ), and more than twice as likely to have less than a high school education ( $48.9 \%$ versus $20.2 \%, p<0.001)$. (Table 1) Peer group 5 patients also more often reported being in fair or poor health $(63.6 \%$ versus $45.5 \%, p<0.001)$ and having poor vision $(p<0.001)$ and hearing $(p=0.001)$. They lived in communities with higher poverty $(p<0.001)$, lower median household incomes $(p=0.02)$, but higher formal education (less than high school; 0.01).

The proportion of hospitals within each peer group that were safety net hospitals varied, with peer group 1 having only 1 safety net hospital $(1.1 \%)$ and peer group 5 having 60 (81.1\%) (Appendix Table 2). Of the 119 safety net hospitals, $50.4 \%$ were in peer group $5,23.5 \%$ in peer group $4,17.6 \%$ in peer group $3,7.6 \%$ in peer group 2 , and $<1 \%$ in peer group 1 (Appendix Table 2).

\section{RSRRs by Peer Groups}

Under the base model, RSRRs varied from $14.6 \%$ for peer group 1 to $15.5 \%$ for peer group 5 (Table 2). Compared with the base model, RSRRs for the patient and full models were 0.1 percentage points, or $0.7 \%$, lower for peer groups 2 (15.1 to $15.0 \%)$ and 4 (14.9 to $14.8 \%)$. The RSRRs for the patient and full models, compared with the base model, were 0.2 percentage points, or $1.3 \%$, lower for peer group 5 (15.5 to $15.3 \%)$. The community model generally did not alter RSRRs, except for peer group 5 (15.5 to $15.4 \%$, a 0.1 percentage point, or $0.7 \%$, decrease).

Distributions of RSRRs under the base and full models across peer groups are presented in Figure 1. These waterfall plots suggest that both the magnitude and the number of hospitals that have changed RSRRs are higher for peer group 5 hospitals, compared with peer group 1 hospitals. Table 3 , which examines the average change in rankings, shows that hospitals in peer group 5, compared with other peer groups, had the largest improvement in measured performance. On average, hospitals in peer groups 4 and 5 with higher RSRRs under the base model generally performed better under the patient, community, and full models. The converse was true for hospitals in peer groups 1,2 , and 3.

\section{RSRRs by Safety Net Hospital Status}

Compared with the base model, the patient and full models decreased the RSRRs for safety net hospitals by 0.2 percentage points, or $1.3 \%$ (from 15.2 to $15.0 \%$ ) (Table 4 ). The community model, compared with the base model, decreased the RSRRs at safety net hospitals by 0.1 percentage points, or $0.7 \%$ (from 15.2 to $15.1 \%$ ). RSRRs for non-safety net hospitals did not vary across the risk adjustment models.

\section{Penalties by Safety Net Hospital Status}

In the base model, fewer non-safety net hospitals were penalized than safety net hospitals (49.1\% versus $51.3 \%$ ) (Table 5). $1.8 \%$ more non-safety net hospitals were penalized under the patient versus base model $(50.0 \%$ versus $49.1 \%$ ), and $0.6 \%$ more under the community and full models (49.4\%). In contrast, $5.1 \%$ fewer safety net hospitals were penalized under the patient versus base model (48.7\% versus $51.3 \%$ ) and $1.8 \%$ under the community and full models $(50.4 \%)$. 
Table 1 Comparison of Patient and Community Characteristics Across by Peer Groups

\begin{tabular}{|c|c|c|c|c|c|c|c|c|}
\hline & Overall & $\begin{array}{l}\text { Peer } \\
\text { group } 1\end{array}$ & $\begin{array}{l}\text { Peer } \\
\text { group } 2\end{array}$ & $\begin{array}{l}\text { Peer } \\
\text { group } 3\end{array}$ & $\begin{array}{l}\text { Peer } \\
\text { group } 4\end{array}$ & $\begin{array}{l}\text { Peer } \\
\text { group } 5\end{array}$ & $\begin{array}{l}p \text { value across } \\
\text { all peer } \\
\text { groups }\end{array}$ & $\begin{array}{l}p \text { value for } \\
\text { peer group } \\
1 \text { vs } 5\end{array}$ \\
\hline Number hospitals & 441 & 90 & 109 & 95 & 73 & 74 & & \\
\hline \multicolumn{9}{|l|}{ Patient characteristics } \\
\hline Mean (SD) age & $77.3(3.6)$ & $77.1(3.0)$ & $77.5(3.6)$ & $77.2(3.4)$ & $76.5(4.1)$ & $77.8(4.1)$ & 0.24 & 0.26 \\
\hline \multicolumn{2}{|l|}{ Race/ethnicity } & $46.9(18.3)$ & $40.4(17.6)$ & $44.4(16.9)$ & $44.2(21.3)$ & $41.8(20.5)$ & 0.14 & 0.09 \\
\hline African-American (\%) & $16.0(24.3)$ & $7.8(14.0)$ & $10.4(17.0)$ & $14.8(20.0)$ & $22.1(27.4)$ & $29.8(35.7)$ & $<0.001$ & $<0.001$ \\
\hline White $(\%)$ & $74.8(29.9)$ & $88.8(15.2)$ & $84.4(22.3)$ & $80.6(23.5)$ & $70.3(30.1)$ & $40.9(34.1)$ & $<0.001$ & $<0.001$ \\
\hline Hispanic (\%) & $5.6(16.9)$ & $0.9(3.0)$ & $3.1(11.1)$ & $2.2(8.3)$ & $5.2(1.5)$ & $19.9(30.6)$ & $<0.001$ & $<0.001$ \\
\hline \multicolumn{9}{|l|}{ Education } \\
\hline $\begin{array}{l}\text { Less than high school } \\
\text { education }(\%)\end{array}$ & $32.4(23.6)$ & $20.2(16.8)$ & $32.1(22.9)$ & $30.7(20.9)$ & $33.6(22.7)$ & $48.9(26.7)$ & $<0.001$ & $<0.001$ \\
\hline $\begin{array}{l}\text { High school education } \\
(\%)\end{array}$ & $35.1(20.8)$ & $35.0(18.9)$ & $31.6(19.2)$ & $40.7(20.8)$ & $35.9(21.0)$ & $32.3(23.9)$ & 0.02 & 0.40 \\
\hline Some college $(\%)$ & $17.3(15.0)$ & $23.8(16.0)$ & $19.3(15.4)$ & $14.9(12.9)$ & $16.0(15.0)$ & $10.7(12.1)$ & $<0.001$ & $<0.001$ \\
\hline College $(\%)$ & $15.3(16.8)$ & $21.1(19.9)$ & $17.1(15.9)$ & $13.8(14.7)$ & 14.5 (18.4) & $8.2(11.1)$ & $<0.001$ & $<0.001$ \\
\hline \multicolumn{9}{|l|}{ Marital status } \\
\hline Never married (\%) & $2.4(6.0)$ & $1.0(3.0)$ & $2.0(4.7)$ & $2.4(5.9)$ & $3.7(6.2)$ & $3.3(9.5)$ & 0.04 & 0.01 \\
\hline Single $(\%)$ & $4.6(2.1)$ & $41.3(21.4)$ & $45.1(20.9)$ & $45.4(18.7)$ & $48.3(22.4)$ & $51.0(23.2)$ & 0.05 & 0.004 \\
\hline Currently married (\%) & $5.2(2.2)$ & $57.7(20.9)$ & $52.7(21.0)$ & $52.2(19.5)$ & $48.0(22.2)$ & $45.6(23.7)$ & 0.004 & $<0.001$ \\
\hline $\begin{array}{l}\text { Mean (SD) Charlson } \\
\text { index score }\end{array}$ & $2.3(0.9)$ & $2.2(0.9)$ & $2.2(0.9)$ & $2.3(0.8)$ & $2.6(1.0)$ & $2.4(0.8)$ & 0.06 & 0.31 \\
\hline Mean (SD) No. ADLs & $1.0(0.6)$ & $0.7(0.4)$ & $0.9(0.6)$ & $0.9(0.5)$ & $1.1(0.6)$ & $1.4(0.8)$ & $<0.001$ & $<0.001$ \\
\hline Mean (SD) No. IADLs & $0.4(0.3)$ & $0.3(0.2)$ & $0.4(0.3)$ & $0.4(0.3)$ & $0.4(0.3)$ & $0.6(0.4)$ & $<0.001$ & $<0.001$ \\
\hline \multicolumn{9}{|l|}{ Mean (SD) health } \\
\hline Fair/poor & $52.5(18.9)$ & $45.5(15.9)$ & $50.9(19.0)$ & $51.3(18.9)$ & $54.0(18.8)$ & $63.6(17.0)$ & $<0.001$ & $<0.001$ \\
\hline Good & $28.4(14.2)$ & $30.0(12.0)$ & $29.4(13.0)$ & 30.7 (14.9) & $29.0(16.2)$ & $21.8(13.5)$ & $<0.001$ & $<0.001$ \\
\hline Very good/excellent & $19.0(12.9)$ & $24.5(13.2)$ & $20.0(13.8)$ & $18.0(12.0)$ & $17.0(9.8)$ & $14.6(12.4)$ & $<0.001$ & $<0.001$ \\
\hline Mean (SD) vision* & $3.2(0.4)$ & $3.0(0.4)$ & $3.2(0.5)$ & $3.1(36.6)$ & $3.2(0.5)$ & $3.3(0.4)$ & $<0.001$ & $<0.001$ \\
\hline Mean (SD) hearing* & $3.0(0.5)$ & $2.9(0.4)$ & $3.0(0.4)$ & $3.0(0.4)$ & $3.0(0.4)$ & $3.1(0.5)$ & 0.010 & 0.001 \\
\hline Cognitive impairment (\%) & $4.3(7.9)$ & $2.9(6.0)$ & $2.4(4.0)$ & $3.8(5.8)$ & $3.9(7.3)$ & $9.5(13.4)$ & $<0.001$ & $<0.001$ \\
\hline Frailty (\%) & $38.7(18.1)$ & $31.7(14.4)$ & $39.3(17.4)$ & $37.4(15.4)$ & $38.6(19.2)$ & $48.4(20.9)$ & $<0.001$ & $<0.001$ \\
\hline $\begin{array}{l}\text { Mean (SD) household } \\
\text { income }(\$ 1000)\end{array}$ & $39.4(24.4)$ & $51.6(29.0)$ & $40.4(22.8)$ & $40.4(25.7)$ & $33.3(14.0)$ & $27.9(20.0)$ & $<0.001$ & $<0.001$ \\
\hline $\begin{array}{l}\text { Mean (SD) household } \\
\text { wealth (\$1000) }\end{array}$ & $\begin{array}{l}378.1 \\
(476.6)\end{array}$ & $\begin{array}{l}559.4 \\
(546.2)\end{array}$ & $\begin{array}{l}377.0 \\
(378.0)\end{array}$ & $\begin{array}{l}443.1 \\
(675.1)\end{array}$ & $\begin{array}{l}248.0 \\
(187.6)\end{array}$ & $\begin{array}{l}204.4 \\
(280.4)\end{array}$ & $<0.001$ & $<0.001$ \\
\hline \multicolumn{9}{|l|}{ Community characteristics } \\
\hline $\begin{array}{l}\text { Mean (SD) primary care } \\
\text { physicians/100,000 resi- } \\
\text { dents }\end{array}$ & $90.4(38.4)$ & $91.1(3 / .3)$ & $89.5(40.9)$ & $93.0(39.4)$ & $91.9(3 / .2)$ & $85.3(36.4)$ & 0.13 & 0.29 \\
\hline $\begin{array}{l}\text { Mean (SD) specialty care } \\
\text { physicians/100,000 resi- } \\
\text { dents }\end{array}$ & $\begin{array}{l}112.8 \\
(75.4)\end{array}$ & $\begin{array}{l}118.2 \\
(57.6)\end{array}$ & $\begin{array}{l}108.8 \\
(88.1)\end{array}$ & $\begin{array}{l}111.9 \\
(71.5)\end{array}$ & $\begin{array}{l}117.0 \\
(79.4)\end{array}$ & $\begin{array}{l}109.1 \\
(76.3)\end{array}$ & 0.88 & 0.44 \\
\hline $\begin{array}{l}\text { Mean (SD) cardiologists/ } \\
100,000 \text { residents }\end{array}$ & $9.5(6.9)$ & $9.9(4.2)$ & $9.7(10.3)$ & $9.6(5.3)$ & $9.8(6.1)$ & $8.2(6.1)$ & 0.56 & 0.12 \\
\hline $\begin{array}{l}\text { Mean (SD) hospital } \\
\text { beds/100,000 residents }\end{array}$ & $\begin{array}{l}368.8 \\
(332.0)\end{array}$ & $\begin{array}{l}410.5 \\
(536.3)\end{array}$ & $\begin{array}{l}360.4 \\
(338.4)\end{array}$ & $\begin{array}{l}380.2 \\
(210.8)\end{array}$ & $\begin{array}{l}358.5 \\
(211.7)\end{array}$ & $\begin{array}{l}326.1 \\
(196.5)\end{array}$ & 0.58 & 0.11 \\
\hline $\begin{array}{l}\text { Mean (SD) of median } \\
\text { household income }\end{array}$ & $\begin{array}{l}45686.7 \\
(8558.6)\end{array}$ & $\begin{array}{l}46523.4 \\
(8096.4)\end{array}$ & $\begin{array}{l}46756.6 \\
(9653.5)\end{array}$ & $\begin{array}{l}45309.1 \\
(7694.8)\end{array}$ & $\begin{array}{l}45792.2 \\
(8651.3)\end{array}$ & $\begin{array}{l}43473.9 \\
(8118.8)\end{array}$ & 0.10 & 0.02 \\
\hline $\begin{array}{l}\text { Proportion not living in } \\
\text { poverty }(\%)\end{array}$ & $85.4(5.4)$ & $87.3(4.5)$ & $87.1(4.2)$ & $85.9(4.2)$ & $84.5(4.7)$ & $80.7(6.9)$ & $<0.001$ & $<0.001$ \\
\hline \multicolumn{9}{|c|}{ Education in the patient's community } \\
\hline $\begin{array}{l}\text { Proportion less than high } \\
\text { school education }(\%)\end{array}$ & $43.7(7.6)$ & $31.5(9.4)$ & $28.8(8.4)$ & $27.9(8.4)$ & $28.2(9.2)$ & $26.4(9.7)$ & $<0.001$ & 0.01 \\
\hline $\begin{array}{l}\text { Proportion with some } \\
\text { college education }(\%)\end{array}$ & $28.7(9.1)$ & $44.7(7.5)$ & $42.3(7.0)$ & $41.4(7.1)$ & $43.6(7.5)$ & $47.6(7.8)$ & 0.006 & $<0.001$ \\
\hline
\end{tabular}

*Vision and hearing are on a scale of 0-6, with a higher number indicating worse vision or hearing $A D L$, activities of daily living; IADL, instrumental activities of daily living

\section{DISCUSSION}

This study found large differences in patient characteristics for hospitals in different peer groups, particularly peer group 5, suggesting that peer group stratification may be particularly helpful to hospitals treating the most vulnerable populations. This may help explain previous studies suggesting that the modified HRRP decreased penalties to a substantial proportion of peer group 5 hospitals. ${ }^{8}$ However, even under the modified HRRP, adjusting for patient functional and social factors differentially influences safety net and non-safety net hospitals. Specifically, RSRRs decreased by $1.3 \%$ for safety net hospitals and did not change for non-safety net hospitals. Further, risk adjusting for patient risk factors increased the percentage of non-safety net hospitals penalized by $1.8 \%$ but decreased the percentage of safety net hospitals penalized by $5.1 \%$. These differences appear to be driven primarily by differences in RSRRs by peer group 5 hospitals, either because they serve more vulnerable patients than hospitals in other 
Table 2 Risk-Standardized Readmission Rates Among Sample Hospitals, by Peer Group

\begin{tabular}{llllllll}
\hline \hline & $\begin{array}{l}\text { Base } \\
\text { model }\end{array}$ & $\begin{array}{l}\text { Patient } \\
\text { model }\end{array}$ & $\begin{array}{l}\text { \% Diff (base } \\
\text { and Pt) }\end{array}$ & $\begin{array}{l}\text { Community } \\
\text { model } \\
\text { \% (SD) }\end{array}$ & $\begin{array}{l}\text { \% Diff (base and } \\
\text { community) }\end{array}$ & $\begin{array}{l}\text { Full } \\
\text { model } \\
\%\end{array}$ & $\begin{array}{l}\text { \% Diff (base and } \\
\text { full) }\end{array}$ \\
\hline Peer group & $14.6(1.5)$ & $14.6(1.2)$ & $0.0 \%$ & $14.6(1.4)$ & $0.0 \%$ & $14.6(1.2)$ & $0.0 \%$ \\
$\begin{array}{l}1 \\
\text { Peer group }\end{array}$ & $15.1(1.7)$ & $15.0(1.4)$ & $-0.7 \%$ & $15.1(1.7)$ & $0.0 \%$ & $15.0(1.4)$ & $-0.7 \%$ \\
2 \\
Peer group & $14.9(1.6)$ & $14.9(1.3)$ & $0.0 \%$ & $14.9(1.6)$ & $0.0 \%$ & $14.9(1.4)$ & $0.0 \%$ \\
3 & & $14.9(1.2)$ & $0.0 \%$ & $14.8(1.0)$ & $-0.7 \%$ \\
$\begin{array}{l}\text { Peer group } \\
4\end{array}$ & $14.9(1.2)$ & $14.8(1.0)$ & $-0.7 \%$ & $15.4(1.6)$ & $-0.7 \%$ & $15.3(1.3)$ & $-1.3 \%$ \\
$\begin{array}{l}\text { Peer group } \\
5\end{array}$ & $15.5(1.7)$ & $15.3(1.3)$ & $-1.3 \%$ & & & & \\
\hline
\end{tabular}

The risk-standardized readmission rates were calculated from the excess readmission ratio, which is the ratio of predicted-to-expected readmissions. The predicted and expected readmission rates were generated through a hierarchical generalized linear model (HGLM) for whether a patient experienced an unplanned all-cause readmission within 30 days of the date of discharge. The base model controls for age, sex, and comorbidity index. The patient model controls for the covariates in the base model, plus four latent factors for patient health status, functional/health status, frailty, and socioeconomic status. The community model controls for the covariates in the base model plus three latent factors for access to care, area income, and area education. The full model controls for the covariates in the base model, plus the patient and community latent factors

peer groups or because they vary in the vulnerability of the patients they serve.

Our results suggest that adding patient social and functional risk factors still changes risk-standardized readmission rates and proportion of safety net hospitals penalized even under the modified HRRP. These results are consistent with previous studies suggesting that although dual eligibility (used to calculate peer groups) is highly correlated with some risk factors, it is less correlated with others, e.g., persons living in poverty. ${ }^{9}$
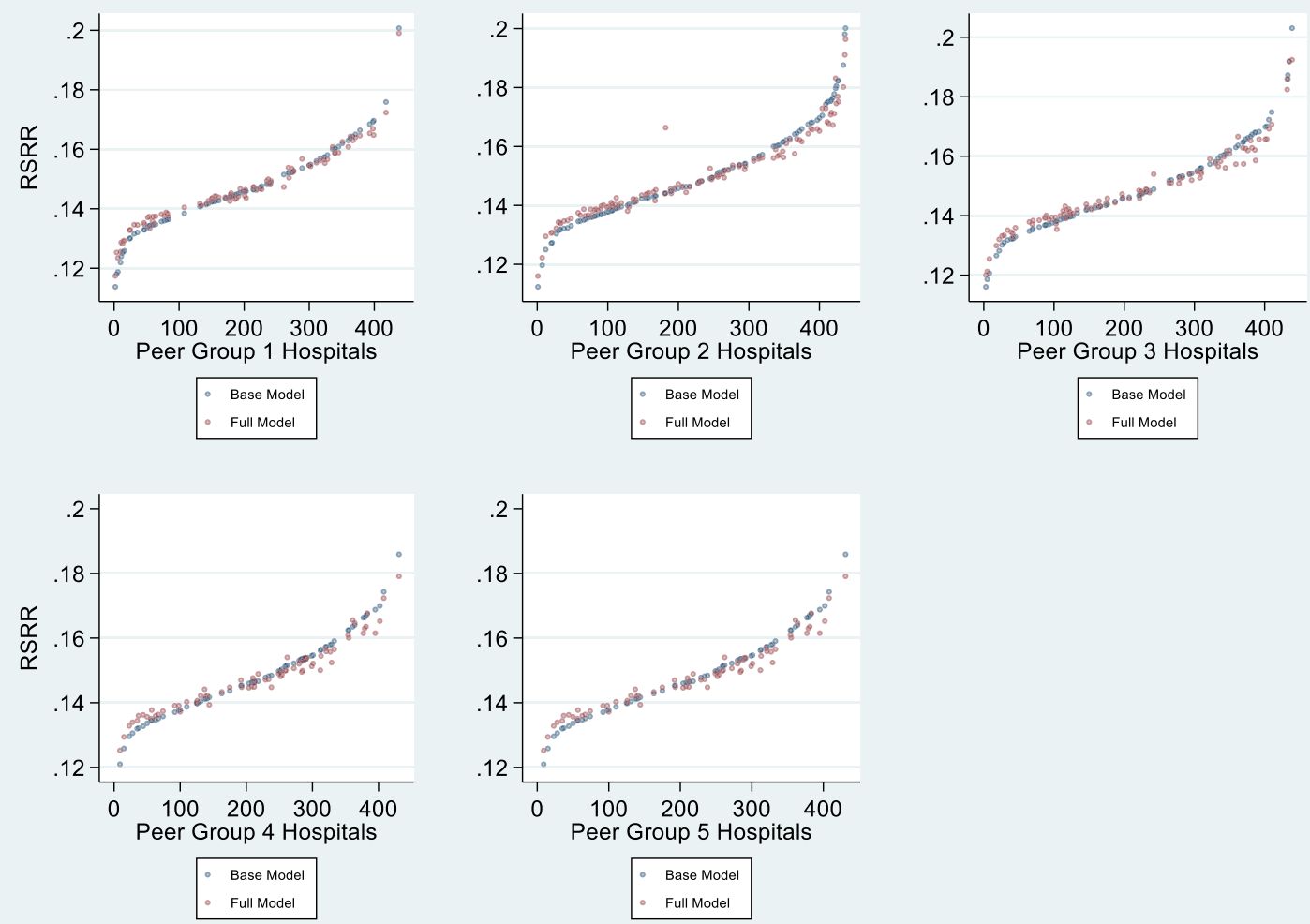

\begin{abstract}
The risk-standardized readmission rates for each hospital were calculated from the excess readmission ratio (ERR), which is the ratio of predicted-to-expected readmissions. The predicted and expected readmission rates were generated through a hierarchical generalized linear model (HGLM) for whether a patient experienced an unplanned all-cause readmissions within 30 days of the date of discharge. The base model controls for age, sex, and comorbidity index. The full model controls for the covariates in the base model, plus patient and community latent factors related to patient health status, functional/health status, frailty, socioeconomic status, access to care, area income, and area education. The waterfall plots rank hospitals within each peer group from lowest to highest RSRRs, and then plots the RSRRs for these ranked hospitals under the base and full models. If the modified HRRP fully captured variability in patient and community risk factors, there would be little difference in the plots. RSRR, risk-standardized readmission rates.
\end{abstract}

Figure 1 Waterfall plots of risk-standardized readmission rates for hospitals in each peer group, under base and full models. 
Table 3 Change in Hospital Rankings of Risk-Standardized Readmission Rates from the Base Model

\begin{tabular}{llll}
\hline \hline $\begin{array}{l}\text { Peer } \\
\text { group }\end{array}$ & $\begin{array}{l}\text { Patient } \\
\text { Mean (min, } \\
\text { max) }\end{array}$ & $\begin{array}{l}\text { Community } \\
\text { Mean (min, } \\
\text { max) }\end{array}$ & $\begin{array}{l}\text { Full } \\
\text { Mean (min, } \\
\text { max) }\end{array}$ \\
\hline 1 & $5.0(-26,37)$ & $-2(-43,15)$ & $2(-42,46)$ \\
2 & $2.8(-64,50)$ & $1.7(-54,193)$ & $3.8(-49,219)$ \\
3 & $1.1(-56,48)$ & $2.1(-21,39)$ & $2.1(-55,60)$ \\
4 & $-3.5(-60,26)$ & $0.3(-31,33)$ & $-2.9(-52,41)$ \\
5 & $-8.1(-82,16)$ & $-3.1(-31,13)$ & $-8.0(-58,21)$ \\
\hline
\end{tabular}

Hospitals were ranked based on their risk-standardized readmission rates (RSRRs) under each of the four models (base, patient, community, and full), with higher rankings indicating higher RSRRs. This table shows the mean, minimum, and maximum change in rankings of the RSRRs for hospitals in each peer group when each of the patient, community, and full models is compared with the base model. A negative number indicates that hospitals in the peer group had lower rankings (improved RSRRs) on average relative to other hospitals, when RSRRs were calculated using a model with additional risk adjustors (e.g., the patient, community, or full models when compared with the base model)

The RSRRs for each hospital were calculated from the excess readmission ratio (ERR), which is the ratio of predicted-to-expected readmissions. The predicted and expected readmission rates were generated through a hierarchical generalized linear model (HGLM) for whether a patient experienced an unplanned all-cause readmissions within 30 days of the date of discharge. The base model controls for age, sex, and comorbidity index. The patient model controls for the covariates in the base model, plus four latent factors for patient health status, functional/health status, frailty, and socioeconomic status. The community model controls for the covariates in the base model plus three latent factors for access to care, area income, and area education. The full model controls for the covariates in the base model, plus patient and community latent factors

$R S R R$, risk-standardized readmission rates

The changes in readmission risk and penalty status are stronger when controlling for the patient-level factors (from HRS) compared with the community-level factors (from AHRF). For instance, adding patient-level risk factors to the base model decreased the percent of safety net hospitals penalized under the modified HRRP by $5.1 \%$, but adding community-level factors decreased this percentage by only $1.8 \%$. This finding is particularly important because community-level income and education are often used as proxies for patient socioeconomic status. Our study suggests that they are not synonymous. This might be because the community-level latent variables do not fully capture all of the heterogeneity in hospital populations that patient-level factors do. Thus, community-level socioeconomic variables may not capture the true vulnerabilities experienced by patients. More research should examine this.

Our study has limitations. First, although the nationally representative HRS data provides rich data on patient-level variables, it has a relatively small sample size, which restricted the size of our analytic sample. Because our sample may be slightly sicker than the general HRS sample (Appendix Table 3), the estimates from our study vary from the population means, thus limiting the generalizability of our study (Appendix Table 3). However, selection bias may have a limited effect on our study results since the outcomes (riskstandardized readmission rates and percent hospitals penalized) are based on a ratio calculated within a larger HRS sample. Furthermore, despite the small sample size, our study suggests that patient-level social and functional risk factors - which are largely unavailable in the broader Medicare discharge files - lend important insights into HRRP.

Second, following previous research, ${ }^{14}$ we used the hospital-wide readmission methodology instead of conditionspecific methodology to increase sample size. This methodology underestimates the percentage of hospitals penalized because only one model assesses excess readmissions, so approximately half of hospitals obtain penalties. Conversely, the condition-specific readmission methodology calculates penalties for excess readmissions for each targeted condition, resulting in a higher proportion of all hospitals penalized. Since more safety net hospitals are penalized than non-safety net hospitals for each targeted condition, ${ }^{1}$ the hospital-wide readmission methodology may underestimate the benefits of additional risk adjustment for safety net hospitals. Thus, our results likely underestimate the differences between peer group hospitals and safety net and non-safety net hospitals, i.e., the true difference between the patient and base models is larger than what we find.

Third, because the study is not causal, the mechanisms driving our findings are unknown. Readmissions and the latent patient and community factors might be influenced by the quality of surrounding providers, and thus, further adjustment

Table 4 Risk-Standardized Readmission Rates Among Sample Hospitals, by Safety Net Status

\begin{tabular}{|c|c|c|c|c|c|c|c|}
\hline & $\begin{array}{l}\text { Base } \\
\text { model }\end{array}$ & $\begin{array}{l}\text { Patient } \\
\text { model }\end{array}$ & $\begin{array}{l}\% \text { Diff (base } \\
\text { and Pt) }\end{array}$ & $\begin{array}{l}\text { Community } \\
\text { model } \\
\% \text { (SD) }\end{array}$ & $\begin{array}{l}\text { \% Diff (base and } \\
\text { community) }\end{array}$ & $\begin{array}{l}\text { Full } \\
\text { model } \\
\%(\text { SD) }\end{array}$ & $\begin{array}{l}\% \text { Diff (base } \\
\text { and full) }\end{array}$ \\
\hline All hospitals & $\begin{array}{l}15.0 \\
(1.5)\end{array}$ & $14.9(1.3)$ & $-0.7 \%$ & $15.0(1.5)$ & $0.0 \%$ & \multirow{3}{*}{$\begin{array}{l}14.9 \\
(1.3) \\
14.9 \\
(1.3) \\
15.0 \\
(1.22)\end{array}$} & $-0.7 \%$ \\
\hline $\begin{array}{l}\text { Non-safety net } \\
\text { hospitals }(N=322)\end{array}$ & $\begin{array}{l}14.9 \\
(1.5)\end{array}$ & $14.9(1.3)$ & $0.0 \%$ & $14.9(1.6)$ & $0.0 \%$ & & $0.0 \%$ \\
\hline $\begin{array}{l}\text { Safety net hospitals }(N \\
=119)\end{array}$ & $\begin{array}{l}15.2 \\
(1.5)\end{array}$ & $15.0(1.2)$ & $-1.3 \%$ & $15.1(1.5)$ & $-0.7 \%$ & & $-1.3 \%$ \\
\hline
\end{tabular}

Risk-standardized readmission rates (RSRRs) for safety net and non-safety net hospitals, which were calculated from the excess readmission ratio, which is the ratio of predicted-to-expected readmissions. The predicted and expected readmission rates were generated through a hierarchical generalized linear model (HGLM) for whether a patient experienced an unplanned all-cause readmission within 30 days of the date of discharge. The base model controls for age, sex, and comorbidity index. The patient model controls for the covariates in the base model, plus four latent factors for patient health status, functional/health status, frailty, and socioeconomic status. The community model controls for the covariates in the base model plus three latent factors for access to care, area income, and area education. The full model controls for the covariates in the base model, plus the patient and community latent factors 
Table 5 Hospitals Penalized Under the Modified HRRP for Safety Net and Non-safety net Hospitals

\begin{tabular}{|c|c|c|c|c|c|c|c|}
\hline & $\begin{array}{l}\text { Base } \\
\text { model }\end{array}$ & $\begin{array}{l}\text { Patient } \\
\text { model }\end{array}$ & $\begin{array}{l}\% \text { Diff (base } \\
\text { and Pt) }\end{array}$ & $\begin{array}{l}\text { Community } \\
\text { model }\end{array}$ & $\begin{array}{l}\% \text { Diff (base and } \\
\text { community) }\end{array}$ & $\begin{array}{l}\text { Full } \\
\text { model }\end{array}$ & $\begin{array}{l}\% \text { Diff (base } \\
\text { and full) }\end{array}$ \\
\hline $\begin{array}{l}\text { All hospitals } \\
\text { Non-safety net } \\
\text { hospitals }(N=322)\end{array}$ & $\begin{array}{l}49.1 \\
(50.1)\end{array}$ & $50.0(50.1)$ & $1.8 \%$ & $49.4(50.1)$ & $0.6 \%$ & $\begin{array}{l}49.4 \\
(501)\end{array}$ & $0.6 \%$ \\
\hline $\begin{array}{l}\text { Safety net hospitals }(N \\
=119)\end{array}$ & $\begin{array}{l}51.3 \\
(50.2)\end{array}$ & $48.7(50.2)$ & $-5.1 \%$ & $50.4(50.2)$ & $-1.8 \%$ & $\begin{array}{l}50.4 \\
(50.2)\end{array}$ & $-1.8 \%$ \\
\hline
\end{tabular}

The total percent of safety net hospitals penalized under the modified HRRP, which is the total percent of safety net hospitals (out of all safety net hospitals) that have an ERR above the median ERR for hospitals within their peer group. Differences are the percent difference between the specific model and the base model. The base model controls for age, sex, and comorbidity index. The patient model controls for the covariates in the base model, plus four latent factors for patient health status, functional/health status, frailty, and socioeconomic status. The community model controls for the covariates in the base model plus three latent factors for access to care, area income, and area education. The full model controls for the covariates in the base model, plus the patient and community latent factors

$H R R P$, hospital readmissions reduction program

is warranted. Alternatively, it could be that stratification fully accounts for patient risk, and our results are observed only because patients with more risk factors cluster in peer group 5 hospitals and these hospitals are of lower quality. ${ }^{22}$ If this is true, adjustment with these factors may mask quality differences, although it may still be useful as a policy matter to do so in order to maintain financial resources of safety net hospitals. More study should be done to establish the causal link between these patient factors and readmissions.

Despite these limitations, this study is important because of its findings that peer group stratification does not sufficiently address patient factors that affect hospitals' readmission risk and penalty status.

Previous studies have disagreed about whether the original HRRP was fair to safety net hospitals. Some researchers suggested that because patient and community factors influenced RSRRs under the original HRRP, the program was unfair to safety net hospitals. ${ }^{1,2}$ Others suggested that the original HRRP was generally fair, since the proportion of safety net hospitals receiving penalties ${ }^{23}$ and readmission model predictiveness ${ }^{24}$ changed only slightly after accounting for these additional risk factors.

We found that $1.4 \%$ of hospitals changed penalty status (compared with $2.3 \%$ under the original HRRP (Appendix Table 4)). If our results generalize, this means that fewer than 50 hospitals under HRRP would change from being penalized to not, or vice versa, although this is likely an underestimate. While 50 hospitals are not a large percent of HRRPparticipating hospitals, our study suggests that hospitals are differentially penalized based on how many vulnerable patients they serve, since the proportion of hospitals penalized changed sign depending on safety net status. Further, since peer group 5 hospitals treat a particularly vulnerable patient population, these hospitals would be particularly helped by including additional patient-level social and functional factors.

Thus, our study may indicate that, although the modified HRRP may have improved the "fairness" of the program through risk stratification, it could do more. Although adding additional patient-level risk adjusters to the HRRP model would accomplish this, it would be resource intensive since they are not currently collected by Medicare. Alternatively,
CMS could further divide peer group 5 so that hospitals within group 5 that serve the most vulnerable patients are in their own peer group. A final possibility is to transfer government funds made to peer group 5 hospitals serving the most vulnerable patients, which would help these hospitals maintain margins despite penalties. ${ }^{25}$ This should be independent of DSH, as high DSH funding did not completely overlap with peer group.

Our findings suggest that the modified HRRP may still not be fair to safety net hospitals, and that there may be important heterogeneity in peer group 5 hospitals. Future research should focus on understanding this heterogeneity, and to explore whether it may be desirable to sub-divide peer group 5 hospitals into additional peer groups.

Corresponding Author: Charleen Hsuan, JD, PhD; Department of Health Policy and Administration, Pennsylvania State University, University Park, PA, USA (e-mail: chsuan@psu.edu).

Funding $\mathrm{CH}$ was supported by the National Center for Advancing Translational Sciences, National Institutes of Health, through Grant UL1 TROO2014. GJH is supported by the Agency for Healthcare Research and Quality (1RO3HSO25838-01A1) and the University of Michigan Older Americans Independence Center Research Education Core (AG024824).

\section{Compliance with Ethical Standards:}

This study was approved by the University of Michigan's institutional review board.

Conflict of Interest: Ninez Ponce is a member of the National Quality Forum's Disparities Standing Committee. CH, TMB, and GJH do not have any potential conflicts of interest to disclose.

Disclaimer: The content is solely the responsibility of the authors and does not necessarily represent the official views of the NIH or AHRQ.

\section{REFERENCES}

1. Joynt Maddox KE, Reidhead M, Hu J, Kind AJH, Zaslavsky AM, Nagasako EM, et al. Adjusting for social risk factors impacts performance and penalties in the hospital readmissions reduction program. Health Serv Res. 2019;54(2):327-36. https://doi.org/10.1111/14756773.13133. 
2. Joynt KE, Jha AK. Thirty-day readmissions-truth and consequences. N Engl J Med. 2012;366(15):1366.

3. Gu Q, Koenig L, Faerberg J, Steinberg CR, Vaz C, Wheatley MP. The Medicare Hospital Readmissions Reduction Program: potential unintended consequences for hospitals serving vulnerable populations. Health Serv Res. 2014;49(3):818-37. https://doi.org/10.1111/1475-6773. 12150.

4. 21st Century Cures Act, Pub. L. 114-255, tit. XV, § 15002130 Stat 1033. 2016. (codified at 42 U.S.C. § 1395ww(q)(3)).

5. Medicare Program; Hospital Inpatient Prospective Payment Systems for Acute Care Hospitals and the Long- Term Care Hospital Prospective Payment System and Policy Changes and Fiscal Year 2018 Rates. 82 Fed. Reg. 38,221-239 (August 14, 2017).

6. Johnston KJ, Joynt Maddox KE. The Role Of Social, Cognitive, And Functional Risk Factors In Medicare Spending For Dual And Nondual Enrollees. Health affairs (Project Hope). 2019;38(4):569-76. https://doi. org/10.1377/hlthaff.2018.05032.

7. Bennett KJ, Probst JC. Thirty-Day Readmission Rates Among DualEligible Beneficiaries. J Rural Health. 2016;32(2):188-95. https://doi. org/10.1111/jrh. 12140 .

8. McCarthy CP, Vaduganathan M, Patel KV, Lalani HS, Ayers C, Bhat DL, et al. Association of the New Peer Group-Stratified Method With the Reclassification of Penalty Status in the Hospital Readmission Reduction Program. JAMA Netw Open. 2019;2(4):e192987-e.

9. Lewis VA, Joynt Maddox K, Austin AM, Gottlieb DJ, Bynum JPW. Developing and Validating a Measure to Estimate Poverty in Medicare Administrative Data. Med Care. 2019;57(8):601-7. https://doi.org/10. 1097/MLR.0000000000001154.

10. Lloren A, Liu S, Herrin J, Lin Z, Zhou G, Wang Y, et al. Measuring hospital-specific disparities by dual eligibility and race to reduce health inequities. Health Serv Res. 2019;54(Suppl 1):243-54. https://doi.org/ 10.1111/1475-6773.13108.

11. Singh S, Lin Y-L, Kuo Y-F, Nattinger AB, Goodwin JS. Variation in the risk of readmission among hospitals: the relative contribution of patient hospital and inpatient provider characteristics. J Gen Intern Med. 2014;29(4):572-8

12. Herrin J, St. Andre J, Kenward K, Joshi MS, Audet AMJ, Hines SC. Community factors and hospital readmission rates. Health Serv Res. 2015;50(1):20-39. https://doi.org/10.1111/1475-6773.12177.

13. Aswani MS, Kilgore ML, Becker DJ, Redden DT, Sen B, Blackburn J. Differential Impact of Hospital and Community Factors on Medicare Readmission Penalties. Health Serv Res. 2018;53(6):4416-36. https:// doi.org/10.1111/1475-6773.13030.

14. Barnett ML, Hsu J, McWilliams JM. Patient Characteristics and Differences in Hospital Readmission Rates. JAMA Intern Med. 2015;175(11):1803-12. https://doi.org/10.1001/jamainternmed.2015. 4660 .
15. Meddings J, Reichert H, Smith SN, Iwashyna TJ, Langa KM, Hofer TP, et al. The Impact of Disability and Social Determinants of Health on Condition-Specific Readmissions beyond Medicare Risk Adjustments: A Cohort Study. J Gen Intern Med. 2017;32(1):71-80. https://doi.org/10. 1007/s11606-016-3869-x.

16. Gilman M, Adams EK, Hockenberry JM, Milstein AS, Wilson IB, Becker ER. Safety-net hospitals more likely than other hospitals to fare poorly under Medicare's value-based purchasing. Health Aff (Project Hope). 2015;34(3):398-405. https://doi.org/10.1377/hlthaff.2014.1059.

17. Yale New Haven Health Services Corporation/Center for Outcomes Research \& Evaluation. 2014 Measures Updates and Specification Report: Hospital-Wide All-Cause Unplanned Readmission measure Version 3.0. New Haven, CT; 2014.

18. Cigolle CT, Ofstedal MB, Tian Z, Blaum CS. Comparing models of frailty: the Health and Retirement Study. J Am Geriatr Soc. 2009;57(5):830-9.

19. Gaskin DJ, Zare H, Vazin R, Love D, Steinwachs D. Racial and Ethnic Composition of Hospitals' Service Areas and the Likelihood of Being Penalized for Excess Readmissions by the Medicare Program. Med Care. $2018 ; 56$ (11):934-43. https://doi.org/10.1097/MLR. 0000000000000988.

20. Nagasako EM, Reidhead M, Waterman B, Dunagan WC. Adding socioeconomic data to hospital readmissions calculations may produce more useful results. Health Aff. 2014;33(5):786-91.

21. Charlson ME, Pompei P, Ales KL, MacKenzie CR. A new method of classifying prognostic comorbidity in longitudinal studies: development and validation. J Chron Dis. 1987;40(5):373-83.

22. Institute of Medicine. Accounting for Social Risk Factors in Medicare Payment: Identifying Social Risk Factors. Washington, DC: The National Academies Press; 2016.

23. Bernheim SM, Parzynski CS, Horwitz L, Lin Z, Araas MJ, Ross JS, et al. Accounting for patients' socioeconomic status does not change hospital readmission rates. Health Aff. 2016;35(8):1461-70.

24. Hoffman GJ, Hsuan C, Braun T, Ponce N. Health Equity and Hospital Readmissions: Does Inclusion of Patient Functional and Social Complexity Improve Predictiveness? J Gen Intern Med. 2019;34(1):26-8. https:// doi.org/10.1007/s11606-018-4635-Z.

25. Bazzoli GJ, Thompson MP, Waters TM. Medicare Payment Penalties and Safety Net Hospital Profitability: Minimal Impact on These Vulnerable Hospitals. Health Serv Res. 2018;53(5):3495-506. https://doi.org/10. $1111 / 1475-6773.12833$

Publisher's Note Springer Nature remains neutral with regard to jurisdictional claims in published maps and institutional affiliations. 